\title{
AS REPRESENTAÇÕES DA VELHICE E SUA INTERFACE COM A MODA: O CASO DA REVISTA CLAUDIA
}

\author{
Débora Pires Teixeira ${ }^{1}$ \\ Rita de Cássia Pereira Farias ${ }^{2}$
}

\begin{abstract}
Resumo:
O presente artigo apresenta a análise das representações da velhice em interface com a temática da moda na revista Claudia, desvelando como ocorrem e quais os seus significados. Foram consideradas duas reportagens (Março/Novembro 2004) da publicação, cujos textos e imagens receberam tratamento analítico pela metodologia de Mendes (2003). As reportagens apresentaram sujeitos ativos, magros, brancos e das classes sociais superiores, ancorados no perfil do "novo velho". Em conclusão, destaca-se que, embora esse perfil representacional possa contestar a normatividade dos padrões de beleza pautados na juventude, a revista confirmou a manutenção de padrões pré-existentes.
\end{abstract}

Palavras-chave: Moda; Representações midiáticas da velhice; Revista Claudia.

\begin{abstract}
:
This article presents the analysis of the representations of old age in interface with the theme of fashion in Claudia magazine, revealing how they occur and what their meanings are. Two articles were considered (March / November 2004) of the publication whose texts and images received analytical treatment by the methodology of Mendes (2003). The reports featured active, thin, white and upper class subjects, anchored in the "new old" profile. In conclusion, it is noteworthy that, although this representational profile may challenge the normativity of beauty standards based on youth, the magazine confirmed the maintenance of pre-existing standards.
\end{abstract}

Keywords: Fashion; Media representations of old age; Claudia magazine.

\section{Introdução}

No livro A velhice, Beauvoir (1976) narra à exclusão dos velhos nas sociedades eurocêntricas e denuncia o silenciamento da velhice ${ }^{3}$. Para a autora, pautada na lógica capitalista que mede o valor do ser humano em relação a sua produtividade, à maioria dos velhos possuía um padrão de vida tão miserável que a maior parte dos indigentes era

\footnotetext{
${ }^{1}$ Doutora (2017-2019) em Economia Doméstica pela UFV. Professora adjunta do Departamento de Economia Doméstica e Hotelaria da Universidade Federal Rural do Rio de Janeiro - UFRRJ (2012 - atual), com foco de atuação em História da Moda e da Indumentária, Processo de Produção do Vestuário, Indústria de Confecção, Artesanato Têxtil, Velhice e Mídia.

${ }^{2}$ Doutora em Antropologia Social pela Universidade Estadual de Campinas, Campinas/SP. Professora Associada do Departamento de Economia Doméstica da Universidade Federal de Viçosa, Viçosa/MG.

${ }^{3}$ Considera-se a velhice como uma etapa do ciclo da vida que, como as demais, é marcada por perdas e ganhos, aproximando-se das proposições teóricas de Beauvoir (1976), que não a reduz ao seu caráter biológico, considerando sua totalidade e, principalmente, o seu aspecto cultural. Para fins de classificação etária, considerase como velho o sujeito com idade igual ou superior aos 60 anos, em atendimento ao Estatuto do Idoso (2003).
} 
constituída por velhos. Assim, "a velhice surge aos olhos da sociedade como uma espécie de segredo vergonhoso, do qual é indecente falar”(...), pois “os velhos não constituem nenhuma potência econômica, não dispõe de recursos para fazer valer seus direitos (...)” (BEAUVOIR, 1976, p.5-8).

Se, em 1970, Beauvoir denunciou a conspiração do silêncio sobre a velhice, em 2004, Debert relata o seu processo de evidenciação no contexto brasileiro do final do século XX. A alteração do status do velho ancora-se no envelhecimento demográfico, na universalização do direito da aposentadoria, na elevação dos valores das pensões e salários dos aposentados, na criação e no aprimoramento da legislação específica, na política de "Envelhecimento Ativo"4 preconizada pela Organização Mundial de Saúde (OMS), na difusão dos programas de terceira idade e no reconhecimento desse grupo etário como um potencial consumidor.

É nesse contexto que surge o "novo velho". Segundo Barros e Castro (2002) e Debert (2004) o "novo velho" é sujeito ativo, autônomo e independente, cuja disposição, capacidade funcional e vitalidade são mantidas pela adoção de novas formas de consumo, consideradas saudáveis e ativas no combate do envelhecimento. São aqueles sujeitos com renda e disposição suficientes para empreender novos projetos e viver experiências inéditas, ligadas ao plano da carreira, afetivo ou do lazer.

Todas essas mudanças na forma de se perceber e representar a velhice impactou sua representação midiática, o que pode ser conferido também nas revistas segmentadas para o público feminino, como é o caso de Claudia.

Até o ano de 2004, o velho era invisibilizado e sub-representado, ocupava pequenos espaços nas revistas, aparecia em fotografias de tamanho reduzido e a temática da velhice era censurada nas reportagens. A representação da velhice, em sua maioria, associava-se a fatos relacionados a trajetórias profissionais. A invisibilidade do velho se dava, sobretudo, nos espaços mais direcionados ao consumo, desprezando-o enquanto potencial consumidor, como se esse público fosse incapaz de consumir.

\footnotetext{
${ }^{4}$ O Envelhecimento Ativo é uma proposta da Organização Mundial de Saúde (OMS) que se refere ao "processo de otimização das oportunidades de saúde, participação e segurança, com o objetivo de melhorar a qualidade de vida à medida que as pessoas ficam mais velhas" (ILC BRASIL, 2016, p. 13).
} 
De acordo com Pires (1998), a diretoria considerava necessário afastar o público de mais idade da revista, visto que os produtos de beleza eram os seus principais financiadores e, no início da década de 1990, uma mulher com idade superior a 50 anos se considerava muito velha pra passar batom ou pintar olhos.

$\mathrm{Na}$ década de 2000, a criação do Estatuto do Idoso representou um marco do enquadramento da velhice em Claudia. As reportagens e entrevistas com velhos prestigiosos tornaram-se mais frequentes, ilustradas por imagens maiores e localizadas em espaços de destaque e notoriedade. A partir de 2004, a temática da velhice foi incluída entre os assuntos debatidos pelo periódico, abrangendo histórias e trajetórias de sujeitos anônimos. Assim, a representação da velhice em Claudia migrou para produção de imagens de atividade, participando da constituição do "novo velho". Esse padrão representacional foi sendo, paulatinamente, incorporado pelas editorias de Moda e Corpo/Beleza.

O presente artigo busca analisar as representações da velhice em interface com a temática da moda na revista Claudia, desvelando como ocorrem e quais os seus significados. Sendo Claudia a terceira revista feminina mais antiga do Brasil, com relevante circulação, continuidade de publicação e com a maior audiência entre as mulheres com mais de 50 anos $(33,4 \% \text { das leitoras })^{5}$, a revista configura-se como um locus privilegiado para o estudo das representações da velhice.

\section{A atuação do velho no mercado da moda}

Com o envelhecimento populacional e o consequente aumento dos consumidores mais velhos, aliando-se as tendências mundiais de representatividade, os profissionais de marketing têm investido na incorporação dos modelos mais velhos, também denominados de modelos "maduros", tanto na moda quanto na publicidade (LOPEZ Y ROYO, 2014; MACKINNEYVALENTIN, 2014; MENDONÇA; FERREIRA, 2014; 2014; POLLINI, 2014; TEIXEIRA; FARIAS; ZAMPIER, 2018).

\footnotetext{
${ }^{5}$ Dados do PUBLIABRIL, 2018.
} 
Grandes nomes da moda e da Alta-costura, ${ }^{6}$ como a Dolce \& Gabbana, têm escolhido pessoas acima de 60 anos para sua representação midiática (revistas, campanhas publicitárias, desfiles, clipes de músicas, dentre outros). Sejam eles iniciantes na profissão e/ou top models consagradas, pela circulação das imagens na mídia, a maioria dos modelos velhos pertence ao sexo feminino, fato relacionado à feminização da velhice, bem como à questão de gênero que permeia o universo da beleza, diretamente relacionado às mulheres (TEIXEIRA; FARIAS; ZAMPIER, 2018).

A inclusão de pessoas com mais de 60 anos como modelo de roupas tem sido considerada uma estratégia acertada pelo marketing na moda, pois além de estar aliada ao discurso midiático da diversidade, pesquisas mostram que os consumidores mais velhos tendem a concordar com a adoção de modelos idosos para promoção de roupas para o público $60^{+}$(EUN-KYOUNG; EUN-YOUNG, 2009), bem como apresentaram maior predisposição a compra de roupas divulgadas por eles (KOZAR; LYNN DAMHORST, 2008).

No mercado internacional, verifica-se a atuação de modelos longevos nas principais semanas de moda e em campanhas publicitárias. Como exemplo, destaca-se a participação da modelo norte-americana Carmen Dell'Orefice, da Ford Models, em campanhas de marcas como Vivienne Westwood, Dior, Jean Paul Gaultier e outros. Outros exemplos são o do ator e modelo chinês Deshun Wang, considerado pelo jornal britânico The Independent como o "avô mais sexy", que desfilou pela primeira vez no China Fashion Week, em Pequim, 2016, e a inglesa Daphne Selfe, agenciada pela britânica Models, com participação em campanhas de marcas como a Olay, Nivea ou Dolce \& Gabbana e em clipes musicais como Queenie Eye, de Paul McCartney (TEIXEIRA; RIGUEIRA; MAFRA, 2018). Na edição de Junho de 2016, em comemoração aos 100 anos da Vogue britânica, a revista incluiu pela primeira vez uma mulher centenária em uma publicidade de moda: Marjorie Bo Gilbert para a grife Harvey Nichols.

Seguindo as tendências internacionais, no Brasil, os modelos velhos se fazem presentes nos prestigiados eventos de moda brasileira. A presença de modelos em idade avançada no São Paulo Fashion Week (SPFW) foi observada a partir de 2004, na coleção da Zapping, bem como nos anos de 2009, 2017 e 2018, nas coleções apresentadas pelo estilista

\footnotetext{
${ }^{6}$ A marca Dolce \& Gabbana utilizou modelos idosas para a sua campanha de primavera/verão 2015.
} 
Ronaldo Fraga. Em 2017, a inclusão de velhos confirmou-se como estratégia de outras marcas, como a UMA, que utilizou a ex-modelo Suzana Kertzer, de 67 anos. A grife Gloria Coelho, divulgando o lançamento de um cosmético anti-idade em parceria com marca Natura, também incluiu mulheres idosas em seu desfile. A edição número 48 do $S P F W$ (Outubro de 2009) contou com a atuação de Étale Wainer, de 87 anos, que desfilou para a Handred, marca que se autodeclara como plural, sem gênero ou idade.

As revistas femininas nacionais têm incorporado mulheres velhas em suas capas e conteúdo, mantendo um padrão estético ligado à juventude. Nas capas analisadas por Teixeira e Farias (2017), cujas personagens centrais eram mulheres de 60 anos ou mais (Revista Malu, de 19 de fevereiro de 2015, com Suzana Vieira e Revista Ana Maria, n.7, 2012, com Ana Maria Braga), as celebridades exibidas foram representadas com corpos joviais, magros, sarados e peles lisas, negando o corpo velho e natural.

\section{Metodologia}

Metodologicamente, a pesquisa possui uma abordagem qualitativa e classifica-se como documental e interpretativa.

No tocante da coleta de dados, durante o mês de Outubro de 2018 foi realizada uma pesquisa exploratória no material do acervo físico da Hemeroteca da Mário de Andrade, localizado na cidade de São Paulo, que agrupa periódicos da editora Abril, incluindo as edições da revista Claudia, de 1961 a atual. A triagem inicial no acervo do periódico compreendeu todas as edições publicadas janeiro 1997- dezembro $2010^{7}$. No total foram examinadas 156 edições da revista, excluindo-se as peças publicitárias.

Para a composição do corpus foram selecionadas duas reportagens nas quais se identificou a presença do velho em interface com a temática da moda: a primeira em Março de 2004, O novo velho; o idoso se reinventou e leva a vida sem monotonia; e a segunda em Novembro de 2004, O quê? Você gastou e quanto, ambas inseridas na seção Reportagens da capa.

\footnotetext{
${ }^{7}$ Este artigo integra parte de uma pesquisa de doutorado intitulada $A$ velhice na revista Claudia: uma análise de 1997 a 2010, no qual o recorte temporal compreende tal período.
} 
A seleção das reportagens se deu mediante a utilização de critérios como aparência e idade cronológica, garantindo que somente as reportagens do conteúdo de moda que apresentassem pessoas com 60 anos ou mais fossem consideradas na análise. Quando a informação etária não estava disponível no texto relacionado à imagem, buscou-se essa informação em fontes externas, como em jornais, revistas e sites.

As imagens e os textos das reportagens foram tratados pela proposta metodológica de Mendes (2013), que utiliza o método de análise de imagens fixas em textos multimodais (verbal e visual), tendo como teoria de base a Semiolinguística. Em muitos casos, o verbal e o icônico são partes de um mesmo gênero de discurso e devem receber um tratamento analítico que os considere como um conjunto. A grade de análise de imagens fixas engloba três dimensões: na primeira, a "macrodimensão situacional", estão os sujeitos do discurso e a situação de comunicação, os elementos que determinam as condições de produção dos discursos sociais, suas formas de circulação e de constituição; a segunda, a "macrodimensão retórico-discursiva" destina-se a recuperação de dados da imagem a fim de que possam ser lidos juntos com o texto, e a terceira "dados paraimagéticos e dados paratextuais" refere-se aos dados encontrados fora do gênero analisado, obtidos em outras fontes como auxilio para o entendimento da imagem (MENDES, 2013).

\section{A representação da velhice e sua interface com a moda: o caso de Claudia}

Lançada em 1961, com uma tiragem de 164.000 exemplares, Claudia inspirou-se nos modelos europeus e norte-americanos. Caracterizada como um periódico sobre temas cotidianos da mulher moderna, rapidamente se tornou o veículo de maior influência sobre o público feminino brasileiro (BRAGA; PRADO, 2011).

Nos anos 1990 a revista expandiu sua abordagem para temas sociais mais pungentes com reportagens sobre denúncias de exploração do trabalho infantil, mulheres espancadas ou abuso sexual na infância, que renderam prêmios à publicação por parte de organizações de direitos humanos (PIRES, 1998; OLIVEIRA, 2014). Para Oliveira (2014), trinta anos depois de seu lançamento, Claudia esboçava um pequeno ensaio que levava à leitora a realidade 
social da mulher brasileira. Concomitantemente, a revista fornecia aconselhamento sobre moda, beleza, decoração e culinária.

Ao longo da década de 2000, Claudia manteve seu propósito de "acompanhar a mudança na vida das mulheres", trazendo temas que seguiram a conquista do mercado de trabalho, a liberação sexual da mulher, o enfrentamento a violência doméstica, dentre outros. Funcionado como um guia de comportamento e consumo, a revista reforçava o perfil da mulher representada em suas páginas e o público que almejava alcançar: urbana, moderna, independente, branca, jovem, magra, pertencente à classe média alta ou alta e que desejava conciliar a carreira profissional com a vida familiar (marido e filhos).

De maneira geral, na década de 1990, o velho era imperceptível nos conteúdos de moda e corpo/beleza, pois Claudia tratava de invisibilizar o velho quando o assunto era a corporalidade. Semelhantemente, o conteúdo de moda utilizava em seus editoriais, preferencialmente, mulheres e homens brancos, magros e jovens, tidos por Goldenberg (2007), como representantes do "corpo capital” para os brasileiros.

A partir de 2004, um novo enquadramento da velhice em Claudia foi inaugurado pela reportagem $O$ novo velho; o idoso se reinventou e leva a vida sem monotonia, da seção Reportagens da capa de Março de 2004. Para denotar concretude a esse formato de representação, a reportagem incluiu relatos de personagens anônimos, considerados como "bons exemplos dessa mudança". Entre eles estava Fredão, apelido de Frederico Paulo Bechter, 66 anos, bancário aposentado e modelo publicitário que desfilou em um dos mais importantes eventos de moda no Brasil: SPFW, de Julho de 2003.

Na revista, a fotografia de Fredão teve como angulação predominante o ângulo de visão médio, no qual a cena observada ocorre na altura dos olhos do leitor (MENDES, 2013). Posicionado no centro esquerdo, Fredão foi fotografado em plano aberto, formato que inclui a figura humana e o cenário onde ela está inserida (MENDES, 2013). A angulação da foto de Fredão (de baixo para cima) ressalta a superioridade do personagem em relação aos demais elementos presentes na foto. $\mathrm{O}$ enquadramento da fotografia também prima pela figura central em detrimento ao cenário, à medida que o personagem se posiciona de pé, inclinado para frente, com os braços abertos, como se fosse saltar da foto em direção ao leitor para abraçá-lo. 
A postura de Fredão inspira movimento e felicidade, bem como denota a centralidade do corpo na profissão de modelo, atividade exercida por ele.

O modelo em questão é um homem com 66 anos, branco, magro, calvo, de cabelos brancos e pele enrugada, que olha para câmera com um sorriso amplo e traja blusa com estampa localizada, mangas destacadas e calça jeans com lavagem estonada. A ausência de mangas e a flexão dos braços valorizam e evidenciam os músculos de Fredão. $\mathrm{O}$ detalhe da corrente no bolso da calça remete ao universo Punk $^{8}$ e finaliza o visual juvenil marcado pela informalidade.

A fotografia foi sobreposta pela legenda (em destaque com letras na cor preta e fundo na cor branca), localizada na parte inferior da imagem, contendo trechos do depoimento do personagem: “Alguém na minha idade não pode vestir o pijama. Virei modelo e arrumei tempo para me divertir - Fredão" (CLAUDIA, Março 2004, p.129). A expressão "vestir o pijama" refere-se à aposentadoria, a inatividade e ao isolamento social. A opção de atuar como modelo de passarela representa uma vivência inovadora para Fredão, o que lhe conferiu “diversão".

A principal atuação de Fredão como modelo ocorreu no desfile da marca de jeans Zapping, na $15^{\mathrm{a}}$ edição da $S P F W$. Além de jovens e adolescentes, o evento contou com dez homens e dez mulheres acima dos 60 anos e com a empresária Gabriella Pascolato (86 anos), que encerrou o desfile. Na reportagem exibida pela revista Claudia, o diretor de marketing da marca, Dipa di Pietro, "justificou a campanha dizendo que a moda tem a obrigação de propor reflexões. É uma postura nossa aceitar as diferenças e quebrar padrões conservadores de comportamento', assegura" (CLAUDIA, Março 2004, p. 131).

No caso de Fredão, a possibilidade de atuação no desfile do mais importante evento de moda brasileira representa a manutenção de sua presença no mercado de trabalho. Seu entusiasmo e empenho como a nova profissão foram destacados pela revista: "[...] atiçando a plateia com alegria e sensualidade contagiantes. Dançou, posou para fotos, deu o recado [...]. Nem mesmo as duas pontes de safena colocadas sete meses antes do desfile impediram seus planos. Ele segue na carreira [....]" (CLAUDIA, Março 2004, p. 131). A atuação como modelo para o "novo velho" representa mais do que uma oportunidade financeira, mas de

\footnotetext{
${ }^{8}$ Tribo jovem de destaque na década de 1980.
} 
inovação profissional que desestabiliza os padrões tradicionais da velhice e estabelece vínculos com a juventude.

Outra participação do velho em interface com o conteúdo de moda se deu em $O$ quê? Você gastou e quanto?, localizada na seção Reportagens da capa de Novembro de 2004. Essa reportagem inaugura a atuação de mulheres velhas como modelos em editoriais de moda: Gloria Kalil, de 61 anos e Constanza Pescolato, de 64 anos. A proposta do editorial era funcionar como um "desafio a cinco experts do mundo da moda: se produzirem inteirinhas com no máximo 250 reais" (CLAUDIA, Novembro 2004, p. 118). Cada profissional deveria selecionar e adquirir peças de roupa e sapatos, além de participar do editorial como modelo, apresentando suas escolhas.

As imagens enquadradas em plano geral ocuparam uma folha inteira, com predomínio da angulação média e vertical. As cenas ocorreram em um estúdio, com fundo colorido, funcionando como um contraste para as composições produzidas pelas consultoras de moda (experts). A composição das fotografias tem como objetivo enaltecer a figura central e suas roupas, propósito do editorial.

A consultora de moda Gloria Kalil, uma mulher magra, branca e de cabelos médios e escuros, foi representada sorridente, em pé, posição frontal com as mãos na cintura, no canto esquerdo da fotografia. Gloria trajava uma regata de malha listrada de preto e branco, sobreposta por um blazer de tecido na cor branca. Na parte inferior, uma saia com a modelagem justa ao corpo, em estampas florais nas cores da blusa. Nos pés, uma sandália plataforma na cor preta. $\mathrm{O}$ visual foi complementado por pulseiras e brincos metálicos, na cor prata. O fundo, em verde oliva, fornecia o contraste visual necessário para evidenciar a produção realizada pela expert.

Na página seguinte, a empresária e consultora de moda Constanza Pascolato uma mulher magra, branca e de cabelos curtos e loiros, foi representada em pé, posição lateral, com as mãos nos quadris, no centro da imagem. Constanza trajava uma blusa de tricô listrada de branco e vermelho, justa ao corpo e com decote canoa. Na parte inferior, uma calça em índigo jeans, com modelagem reta. Nos pés, um chinelo com acabamento em corda. O fundo, em uma tonalidade de vermelho semelhante à estampa da blusa, destacava a cor da pele da modelo. 
A atuação de duas velhas nesse editorial esteve ligada à profissão de consultora de moda, cuja função era apresentar soluções visuais articuladas com as tendências de moda do momento, com baixo custo. Tal como ocorreu com Fredão, à permanência dessas mulheres no mercado de trabalho reitera a noção de atividade, característica principal do "novo velho", conforme preconiza a política do Envelhecimento Ativo, defendida pela Organização Mundial de Saúde - OMS.

Para Debert (2004) essa reaproximação com o mercado de tratabalho é guiada por um novo ideal produtivo. O pressuposto defendido pela gerontologia é o de que o abandono do trabalho leva a uma situação traumática que envolve a perda das identidades e do equilíbrio psicológico. Conforme Haddad (2017), o trabalho passa a ser indicado como a melhor terapia para o envelhecimento. Desta forma, a proposta da abolição da aposentadoria por tempo de serviço se faz presente em discursos de gerontólogos.

Em suma, no corpus analisado, a imagem do velho em interface com a moda confirma a representação da velhice que migra da invisibilidade, até a década de 1990, para a constituição do "novo velho", a partir de 2004. Ademais, nota-se que ambas as reportagens estavam inseridas na seção de maior destaque da publicação: a seção Reportagens da capa, o que evidencia a mudança de enquadramento da velhice na revista.

Não se pode negar que a inclusão do velho no conteúdo de moda é um ganho na representação da velhice. No entanto, questiona-se: quais são os corpos representados nesses espaços? A representação da velhice em ambas a reportagens esteve ligada a sujeitos magros, brancos e das classes sociais superiores. Entre as mulheres, as personagens foram retratadas sem rugas e/ou flacidez aparentes e, na maioria das vezes, com cabelo tingido. Ou seja, ao mesmo tempo em que promove a inclusão de mulheres com idade superior a 60 anos, os conteúdos de moda reafirmam a existência de um padrão de representação dos corpos femininos nas revistas segmentadas e direcionadas para esse público.

No discurso produzido pela revista, além do reforço ao ideal produtivo ligado à atividade e a manutenção dos velhos no mercado de trabalho, o "novo velho" reforça a importância da preservação de uma estética jovem seja pelo uso das roupas e dos acessórios ou pelo mascaramento de sinais de senescência (cabelos tingidos). É o que Debert (2004) denomina de "reprivatização da velhice", ou seja, um processo que responsabiliza os sujeitos 
pelo seu envelhecimento, no qual os dramas dos velhos se transformam em responsabilidades dos indivíduos que negligenciaram seus corpos e foram incapazes de se envolver em atividades motivadoras. Assim, “a reprivatização da velhice transforma o direito de escolha em um dever de todos, em uma realidade inescapável a que estamos todos condenados" (DEBERT, 1999, p. 81).

Nesse sentido, Mackinney-Valentin (2014) questiona se a inclusão de modelos subversivos (velho, deficiente, gordo, desajeitado etc.) é sintomática de uma mudança da ditadura da perfeição da moda em direção a uma maior relatividade na percepção e representação da beleza, ou se essa recente mudança visual é apenas uma imagem na qual a indústria da moda articula questões de identidade e significação para fins de vantagens competitivas.

Com o aumento da independência do consumidor faz-se necessário que o marketing de moda reflita o consumidor nas campanhas e nas passarelas. Assim, o uso de modelos subversivos representa uma absorção de estratégia social pelo marketing de moda, na tentativa de apelar ao comportamento contemporâneo do consumidor, espelhando-o (MACKINNEYVALENTIN, 2014).

Segundo Debert (2004), a tendência contemporânea é que a mídia abandone a representação antagônica da velhice, caracterizada pela coexistência de perfis de dependência, abandono, fragilidade, decrepitude, poder e atividade, e passe a representá-los de maneira mais positivas. Essas imagens do envelhecimento, que acompanham a construção da chamada terceira idade, ocupam um espaço cada vez maior na mídia e abrem novos campos para a constituição de mercados de consumo ainda pouco explorados (DEBERT, 2003). Nessa lógica, a imagem da velhice é guiada pela perspectiva do "idoso como fonte de recurso" (DEBERT, 2004, p.206).

A partir do momento em que foi considerado como potencial consumidor, o velho passou a assumir uma nova imagem e a ter outra importância para o mercado. No entanto, seu retrato não generalizou para todos os sujeitos com 60 anos ou mais, independentemente de renda financeira. Pode-se refletir que não é propriamente o velho o alvo da mídia, mas os consumidores em potencial que, na atualidade, devido a rendimentos mais seguros, são capazes de financiar seu consumo (BRANDÃO, 2007). 
Pesquisas norte-americanas, realizadas na década de 1990, sobre o perfil do consumidor com mais de 60 anos mostraram que somente uma parcela de consumidores interessa ao mercado ("masters consumers"), pois configuram o grupo que possui maior poder de consumo e veem na maturidade uma oportunidade de vivenciar novas experiências guiadas pelo prazer e oportunizadas pelas boas condições físicas, mentais e econômicas. Os velhos que despertam pouco interesse em termos mercadológicos são os que estão abaixo do nível de pobreza (“disadvantage”) e "os de pouca saúde” (DEBERT, 2003).

Embora não se possa negar que a visibilização da velhice e a superação do perfil "velho decadente" seja um ganho da representação e da constituição da identidade do velho, para Debert (2004) a visão do "idoso como fonte de recursos" encobre a miséria. Featherstone e Hepworth (1995) e Debert (2004) advertem que a imagem do velho construída pelas revistas contrasta com a realidade de uma parcela significativa da população envelhecida: os decrépitos, doentes e os miseráveis, causando sofrimento e a exclusão daqueles que não correspondem ao padrão do "novo velho".

Segundo Debert (2004), a imagem do envelhecimento bem-sucedido através da mídia não oferece instrumentos capazes de enfrentar os problemas relativos a perda de habilidades cognitivas e de controles físicos e emocionais que estigmatizam o velho, e que são fundamentais na nossa sociedade, para que um indivíduo seja reconhecido como um ser autônomo, capaz de um exercício pleno dos direitos de cidadania.

\section{Considerações Finais}

Nas reportagens analisadas, a representação da velhice em interface com a temática da moda esteve atrelada a construção do perfil de atividade representado pelo "novo velho", que englobou a manutenção de atividades laborativas e a preservação de uma estética jovem, seja pelo uso de roupas, acessórios ou pelo mascaramento de sinais de senescência (cabelos tingidos).

Nesses espaços, os corpos representados se limitaram aos magros, brancos e das classes sociais superiores. Entre as mulheres, manutenção de atributos corporais jovens se fez 
presente. Assim, ao incluir mulheres velhas, Claudia reforçou a existência de um padrão específico e dominante entre as revistas femininas.

A representação do velho em uma temática dominada pela juventude, como é o caso da moda, pode contribuir com a ruptura de estigmas negativos associados à velhice. Para tanto, deve-se considerar uma atuação que possibilite a autonomia dos sujeitos e que rompa com o padrão de beleza único e uniformizador, fazendo com que a diversidade e a pluralidade da velhice sejam respeitadas e valorizadas.

\section{Referências}

BARROS, Regina Duarte Benevides de Barros; CASTRO, Adriana Miranda. Terceira Idade: o discurso dos experts e a produção do "novo velho". Estudos interdisciplinares do envelhecimento, Porto Alegre, v. 4, p. 113-124, 2002.

BEAUVOIR, Simone. A velhice. 2 ed. São Paulo: Difusão Européia do Livro, 1976.

BRAGA, João; PRADO, André L. História da Moda no Brasil: das influências às autorreferências. São Paulo: Pyxis Editorial. 2011.

BRANDÃO, Hermínia. A Mídia e o Idoso. In: Papaleo Netto, Mateus. Tratado de Gerontologia. São Paulo: Editora Atheneu, 2007. p. 823-830.

DEBERT, Guita Grin. A invenção da terceira idade e a rearticulação de formas de consumo e demandas políticas. Revista Brasileira de Ciências Sociais. São Paulo, v. 12, n. 34, p. 39-56, jun. 1997.

DEBERT, Guita Grin. A Reinvenção da Velhice: socialização e processos de reprivatização do envelhecimento. São Paulo: Edusp/Fapesb, 2004.

DEBERT, Guita Grin. O velho na propaganda. Cadernos Pagu, n.21. p.133-155. 2003.

GOLDENBERG, Miriam. O corpo como capital. Estudos sobre gênero, sexualidade e moda na cultura brasileira. Barueri: Estação das Letras e Cores, 2007.

EUN-KYOUNG, Seo; EUN-YOUNG, Jang. Middle-Aged of the British Women's Apparel Purchase Situation Analysis. Journal of Fashion Business, v.13, n. 3, p. 99-108. 2009.

FEATHERSTONE, Mike; HEPWORTH, Mike. Images of positive aging: a case study of Retirement Choice magazine. In: FEATHERSTONE, Mike; WERNICK, Andrew (org.). Images of aging: cultural representations of later life. London: Routledge. 1995. p. 29-47. 
HADDAD, Eneida G. de Macedo. A ideologia da velhice. 2 ed. Cortez: São Paulo. 2017.

ILC - BRASIL, CENTRO INTERNACIONAL DE LONGEVIDADE DO BRASIL.

Envelhecimento Ativo: um marco político em resposta à revolução da longevidade. Rio de Janeiro: ILC BRASIL. 2015.

KOZAR, Joy M.; LYNN DAMHORST, Mary. (2008), Older women's responses to current fashion models. Journal of Fashion Marketing and Management, v 12, n. 3, p. 338-350, 2008

LOPEZ Y ROYO, Alessandra Bruni. Over 50 and doing what? Reflections on being a mature. In: International Women, Ageing and Media Research Summer School, 2324 July 2013.

MACKINNEY-VALENTIN, Maria. Face value: subversive beauty ideals in contemporary fashion marketing. Fashion, Style \& Popular Culture, v. 1, n.1, pp. 13-27, 2014.

MENDES, Emília. Análise do discurso e iconicidade: uma proposta teórico-metodológica. Mendes, Emília et al. (Orgs). Imagem e discurso. Belo Horizonte: FALE/UFMG. 2013. p. 125-56.

MENDONÇA, Maria Luiza Martins. Imagens do envelhecimento: como a mídia brasileira representa a mulher de meia idade. Informação \& Comunicação, v. 14, n. 2, p. 139-153, jul./dez. 2011.

NUMMELIN, Johanna. Business potential in senior services. International Journal of Strategic Property Management, v. 9, n. 3, p.191-200, 2005.

OLIVEIRA, Cláudia N. B. A. Um olhar sobre o olho que olha: adorno do Ethos, Autoridade do Pathos e Mudanças Discursivas na constituição do feminino na Revista Claudia. Tese (Doutorado) - Pontifícia Universidade Católica de São Paulo/PUC-SP, São Paulo, 2014.

PIRES, André. Velhos em Revista: envelhecimento e velhice nas páginas de Claudia e Playboy (anos 80 e 90). Dissertação (Mestrado) - Instituto de Filosofia e Ciências Humanas, Universidade Estadual de Campinas. Campinas/SP, 1998.

POLLINI, Denise. O envelhecimento e a moda: tecendo reflexões. Mais 60 Estudos sobre o Envelhecimento, v. 25, n. 61, p. 8-25, 2014.

PUBLIABRIL. Revista Claudia. PubliAbril. Disponível em: http://publiabril.abril.com.br/marcas/claudia. Acesso em: 02 mai. 2018. 
TEXEIRA, Débora Pires; FARIAS, Rita de Cássia P.; Zampier, Ronan L. Construção da imagem do velho na mídia: representatividade ou estímulo ao consumo? Vértices, v. 21, n 3, p.385-397, 2018.

TEXEIRA, Débora Pires; FARIAS, Rita de Cássia Pereira. Como (não) ser velha: o consumo de tecnologias do rejuvenescimento e as revistas femininas. In: Seminário Nacional Família e Políticas Sociais no Brasil, 1, 2017. Viçosa-MG. Anais [...]. Viçosa: UFV. Setembro de 2017.

TEXEIRA, Débora Pires; RIGUEIRA, Marta M. Gonçalves; MAFRA, Simone Caldas Tavares. A longevidade na mídia: a representação da velhice e a profissão de modelo. Workshop do Grupo de Pesquisa "Desenvolvimento Humano, Social e Vida Cotidiana, 3, 2018, Viçosa/MG. Anais [...]. UFV: Viçosa/MG. Abr. 2018

Texto recebido em: $26 / 10 / 2019$

Texto aprovado em: 06/02/2020 